Abstract

\title{
A Smart Colorimetric Sensor for the Enzymatic Detection of L-Lactate in Screening Analysis ${ }^{+}$
}

\author{
Giulia Selvolini 1,* , Ana-Maria Drăgan ${ }^{2}$, Gheorghe Melinte ${ }^{1,2}$, Cecila Cristea ${ }^{2}$ and \\ Giovanna Marrazza 1,3 \\ 1 "Ugo Schiff" Chemistry Department, University of Florence, Via Della Lastruccia 3, \\ 50019 Sesto Fiorentino (FI), Italy; Melinte.Gheorghe@umfcluj.ro (G.M.); giovanna.marrazza@unifi.it (G.M.) \\ 2 Analytical Chemistry Department, Faculty of Pharmacy, "Iuliu Hatieganu" University of Medicine and \\ Pharmacy, Strada Louis Pasteur 4, 400000 Cluj-Napoca, Romania; ana.dragan@umfcluj.ro (A.-M.D.); \\ ccristea@umfcluj.ro (C.C.) \\ 3 Istituto Nazionale Biostrutture e Biosistemi (INBB), Unit of Florence, Viale Delle Medaglie D’Oro 305, \\ 00136 Roma, Italy \\ * Correspondence: giulia.selvolini@unifi.it; Tel.: +39-055-457-3384 \\ + Presented at the 1st International Electronic Conference on Biosensors, 2-17 November 2020; Available \\ online: https://iecb2020.sciforum.net/.
}

Published: 2 November 2020

\begin{abstract}
Lactate is a metabolite biomarker of tissue oxygenation and it can be used in medicine to evaluate a pathology or in sport activities to evaluate physical performance. Lactate level assessment is also important for food industry. This acid is found in food and beverages and the concentration level can be correlated with the freshness, stability and quality of several products. In this work, we present a smartphone-based enzymatic biosensor utilizing the unique colorimetric properties of the poly(aniline-co-anthranilic acid) (p(ANI-co-AA)) composite film coupled with lactate oxidasehorseradish peroxidase (LOx-HRP) enzymes. The enzymes are immobilized on the composite polymer film by adsorption and they catalyze a reversible redox color change of the host polymer from green to blue in the presence of L-lactate as the substrate. A smartphone was applied as color detector, for image acquisition and data handling. The free-of-charge Color Grab ${ }^{\circledR}$ application for Android OS was used to enable an easy and clear display of the sensor's response, indicating remarkable changes in the optical features. The results were confirmed by spectrophotometric measurements. The developed colorimetric enzymatic biosensors were studied and optimized in relation to different experimental parameters. Moreover, the colorimetric enzymatic biosensor was applied to real matrices analysis. It has been shown by these studies that the colorimetric biosensors are promising as quick and simple tests for handheld analysis in various fields.
\end{abstract}

Keywords: L-lactate; copolymer; enzymatic sensor; smartphone

Publisher's Note: MDPI stays neutral with regard to jurisdictional claims in published maps and institutional affiliations.

(C) 2020 by the authors. Licensee MDPI, Basel, Switzerland. This article is an open access article distributed under the terms and conditions of the Creative Commons Attribution (CC BY) license (http://creativecommons.org/licenses/by/4.0/). 